\title{
The epidemiology of acinetobacter infections in Hong Kong
}

\author{
H. SIAU, K. Y. YUEN, S. S. Y. WONG, P. L. HO and W. K. LUK* \\ Department of Microbiology, University of Hong Kong, Pathology Building, Queen Mary Hospital Compound, \\ Pokfulam Road and *Department of Microbiology, Queen Mary Hospital, Pokfulam Road, Hong Kong
}

\begin{abstract}
A retrospective survey was conducted of the characteristics of acinetobacter infections in Hong Kong - seasonal and geographic distributions, frequency of isolation from various body sites, antimicrobial susceptibility and molecular epidemiology. Most (80\%) isolates of Acinetobacter spp. belonged to DNA groups 2 ( $A$. baumannii) or 13, as defined by growth at $44^{\circ} \mathrm{C}$. An increased isolation rate in summer was related to higher ambient temperatures. The notion that acinetobacters are opportunist nosocomial pathogens was supported by the body site- and ward-specific distributions, which were similar to those of Pseudomonas aeruginosa and in marked contrast to those of coagulase-negative staphylococci and Escherichia coli. Typing of Acinetobacter isolates by arbitrary-primed polymerase chain reaction revealed extensive genotypic polymorphism, suggesting that numerous unrelated strains were circulating between patients. In view of the association with a high incidence of polymicrobial bacteraemia and multiresistance to antibiotics, a careful selection of appropriate antibiotics in combination is necessary for empirical therapy of infections caused by Acinetobacter spp.
\end{abstract}

\section{Introduction}

The genus Acinetobacter - which comprises nonfermentative gram-negative bacteria of low pathogenicity - has attracted recent clinical and research interest as members of the genus are implicated increasingly as nosocomial pathogens. Ubiquitous in soil and water, Acinetobacter spp. are also part of the indigenous flora of human skin. The remarkable resistance of some of these micro-organisms to prolonged desiccation and to multiple antibiotics has allowed them to adapt successfully to the hospital niche $[1,2]$. The genus comprises at least 17 DNA groups (genomic species) [3-5], of which A. baumannii (DNA group 2) - a glucose oxidiser that is able to grow at $44^{\circ} \mathrm{C}-$ is involved most frequently in hospital outbreaks [6-9].

Several studies on the epidemiological and clinical features of acinetobacter infections have been published [10-15]. Unlike the low incidence of Acinetobacter spp. isolated from in-patients in the West [10], an endemic presence of these organisms has been observed in this hospital [16]. As comprehensive data about the prevalence of these organisms amongst

Received 9 Aug. 1995; revised version accepted 11 Oct. 1995.

Correspondence should be sent to Dr H. Siau. hospitalised patients in this locality are lacking, a retrospective survey was conducted to elucidate the role of Acinetobacter spp. as opportunist nosocomial pathogens. The annual incidence of isolation and seasonal prevalence during the 5-year period 19901994 was determined. The relative distribution of Acinetobacter spp. with respect to isolation site and geographic location within the hospital, either in the general ward or intensive care unit (ICU), was compared to those of three other established nosocomial pathogens (Pseudomonas aeruginosa, coagulasenegative staphylococci and Escherichia coli). As the spectrum of infection caused by these organisms differs $-P$. aeruginosa is involved mainly in wound, respiratory and urinary tract infections; coagulasenegative staphylococci are linked usually to foreign device-related infections; and $E$. coli is related generally to intra-abdominal and urinary tract infections - they served as references for comparison. The epidemiological relationships between some of the Acinetobacter isolates were investigated by arbitraryprimed polymerase chain reaction (AP-PCR).

\section{Materials and methods}

This study was performed at the Queen Mary Hospital, a tertiary teaching hospital with 1350 beds that serves a population of 1.5 million in Hong Kong. Bacteriologi- 
cal data from 1 Jan. 1990 to 30 Nov. 1994 were retrieved from the microbiology laboratory database and reviewed. When multiple isolates of the same organism from the same site were reported for one patient, only a single entry was included. Likewise, only the first positive blood culture from the same patient was included in the enumeration of bacteraemic episodes.

\section{Bacteriology}

Acinetobacter spp. were identified routinely as nonmotile, oxidase-negative gram-negative coccobacilli that grew only in aerobic incubation. The ability of each isolate to oxidise glucose in Hugh and Leifson's medium was tested. The isolates were reported as glucose-oxidising or non-glucose-oxidising strains of Acinetobacter spp. Since early 1995, non-haemolytic glucose-oxidising isolates from blood, wound, respiratory and urinary tract specimens were tested for growth at $44^{\circ} \mathrm{C}$. These temperature-tolerant isolates were identified presumptively as $A$. baumannii (DNA group 2 ) or the unnamed DNA group 13 [5]. There was no further attempt to differentiate the isolates by DNA hybridisation or extensive substrate assimilation tests. Isolates of $P$. aeruginosa, coagulase-negative staphylococci and E. coli were identified according to standard criteria [17]. When isolated from respiratory tract and wound specimens, unless Gram's stain of the specimen smear showed bacteria and a significant increase in the number of white blood cells, Acinetobacter spp., $P$. aeruginosa and coagulase-negative staphylococci were regarded as contaminants and thus not reported. Similarly, for urinary tract specimens, these organisms were reported only in instances of significant bacteriuria $\left(>10^{5} \mathrm{cfu} / \mathrm{ml}\right)$. In addition, they were also reported in catheter culture-positive specimens $(>15 \mathrm{cfu})$.

\section{Antimicrobial susceptibility testing}

In-vitro susceptibility testing was performed routinely in this laboratory on all significant Acinetobacter isolates by the disk diffusion method recommended by the National Committee for Clinical Laboratory Standards [18]. Antibiotic disks were obtained from Becton Dickinson and contained ampicillin $(10 \mu \mathrm{g})$, cephalothin $(30 \mu \mathrm{g})$, cefuroxime $(30 \mu \mathrm{g})$, ceftriaxone $(30 \mu \mathrm{g})$, ceftazidime $(30 \mu \mathrm{g})$, amoxycillin + clavulanic acid $(20$ and $10 \mu \mathrm{g}$, respectively), imipenem $(10 \mu \mathrm{g})$, gentamicin $(10 \mu \mathrm{g})$, netilmicin $(30 \mu \mathrm{g})$, amikacin $(30 \mu \mathrm{g})$, trimethoprim + sulphamethoxazole (1.25 and $23.75 \mu \mathrm{g}$, respectively) or ofloxacin $(5 \mu \mathrm{g})$. For quality control, the antibiotic susceptibility of the standard P. aeruginosa strain ATCC 27853 was tested routinely.

\section{Arbitrary-primed PCR (AP-PCR)}

In total, 60 clinical strains isolated from blood (28), respiratory tract (14), urinary tract (10) and wound (8) specimens - presumed to be $A$. baumannii or the unnamed DNA group 13 because of growth at $44^{\circ} \mathrm{C}-$ were retrieved from stock cultures for AP-PCR. A. baumannii strain ATCC 19606 served as an internal control in every experiment. Each isolate was streaked first on blood agar and incubated at $37^{\circ} \mathrm{C}$ overnight. One colony of each isolate was suspended in $1 \mathrm{ml}$ of sterile water. A crude DNA extract was obtained by heating the bacterial suspension at $95^{\circ} \mathrm{C}$ for $15 \mathrm{~min}$. After centrifugation at $12000 \mathrm{~g}$ for $15 \mathrm{~min}, 2 \mu \mathrm{l}$ of the supernate were added to $48 \mu \mathrm{l}$ of PCR reaction mixture containing $10 \mathrm{mM}$ Tris- $\mathrm{HCl}(\mathrm{pH} 8.0), 50 \mathrm{mM} \mathrm{KCl}$, $1.5 \mathrm{mM} \mathrm{MgCl} 2,200 \mu \mathrm{M}$ (each) of the four deoxynucleoside triphosphates (Pharmacia), $20 \mu \mathrm{M}$ (GTG) primer (Department of Molecular Medicine, King's College, University of London) and $2.5 \mathrm{U}$ of Taq polymerase (Perkin-Elmer Cetus, Emeryville, USA). A negative control containing the reaction mixture without any added DNA sample was included in all experiments. In preliminary studies, (GTG) 5 yielded better banding patterns than two other primers tested: T7 (5'-GTA ATA CGA CTC ACT ATA G-3') and LD (5'-CCA CAC GCG CAC ACG GGA-3'). PCR was performed in a Gene Cycler (BioRad) with the following programme: 30 cycles of denaturation at $94^{\circ} \mathrm{C}$ for $1 \mathrm{~min}$, low stringency annealing at $45^{\circ} \mathrm{C}$ for $2 \mathrm{~min}$ and extension at $72^{\circ} \mathrm{C}$ for $1 \mathrm{~min}$. The reaction was terminated with a final extension cycle at $72^{\circ} \mathrm{C}$ for $6 \mathrm{~min}$. The PCR products were separated by electrophoresis at $100 \mathrm{~V}$ for $1.5 \mathrm{~h}$ in an agarose $2 \% \mathrm{w} / \mathrm{v}$ gel, and detected by staining with ethidium bromide.

\section{Results}

\section{Incidence}

Data were available for 7475 strains of Acinetobacter isolated between Jan. 1990 and Nov. 1994. The average annual incidence of isolation was 298/10000 hospital admissions (Table 1). Acinetobacter spp. accounted for $34.9,11.3$ and $7.4 \%$ of non-fermenters, gram-negative bacilli and all bacteria, respectively. Acinetobacter spp. capable of oxidising glucose made up $94.5 \%$ of all isolates and $83.8 \%$ of the isolates tested ( 202 of 241 isolates) were able to grow at $44^{\circ} \mathrm{C}$. Hence, with regard to genotype, most isolates were presumed to belong to the temperature-tolerant genospecies $A$. baumannii (DNA group 2) or the unnamed DNA group 13 [5]. Unless stated otherwise, the following sections focus specifically on the glucose-oxidising strains of Acinetobacter spp.

\section{Seasonal prevalence}

A seasonal variation in the isolation rate of Acinetobacter spp. was observed in the general ward (Fig. 1). The largest number of isolates was obtained during July-Oct., 1990-1993. The peak period corresponded with an increased number of isolates from all body sites. However, in the ICU, apart from a peak in Nov. 
Table 1. The incidence and glucose oxidation capability of Acinetobacter spp. isolated during 1990-1994

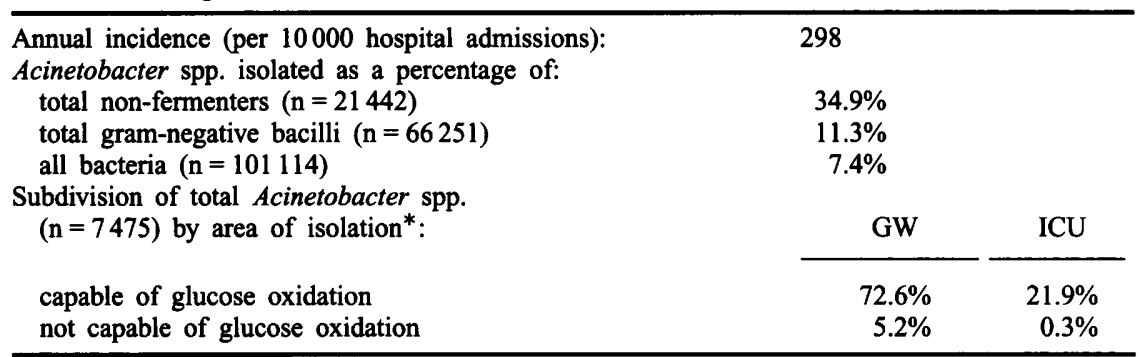

${ }^{*} \mathrm{GW}$, general ward; ICU, intensive care unit.

a

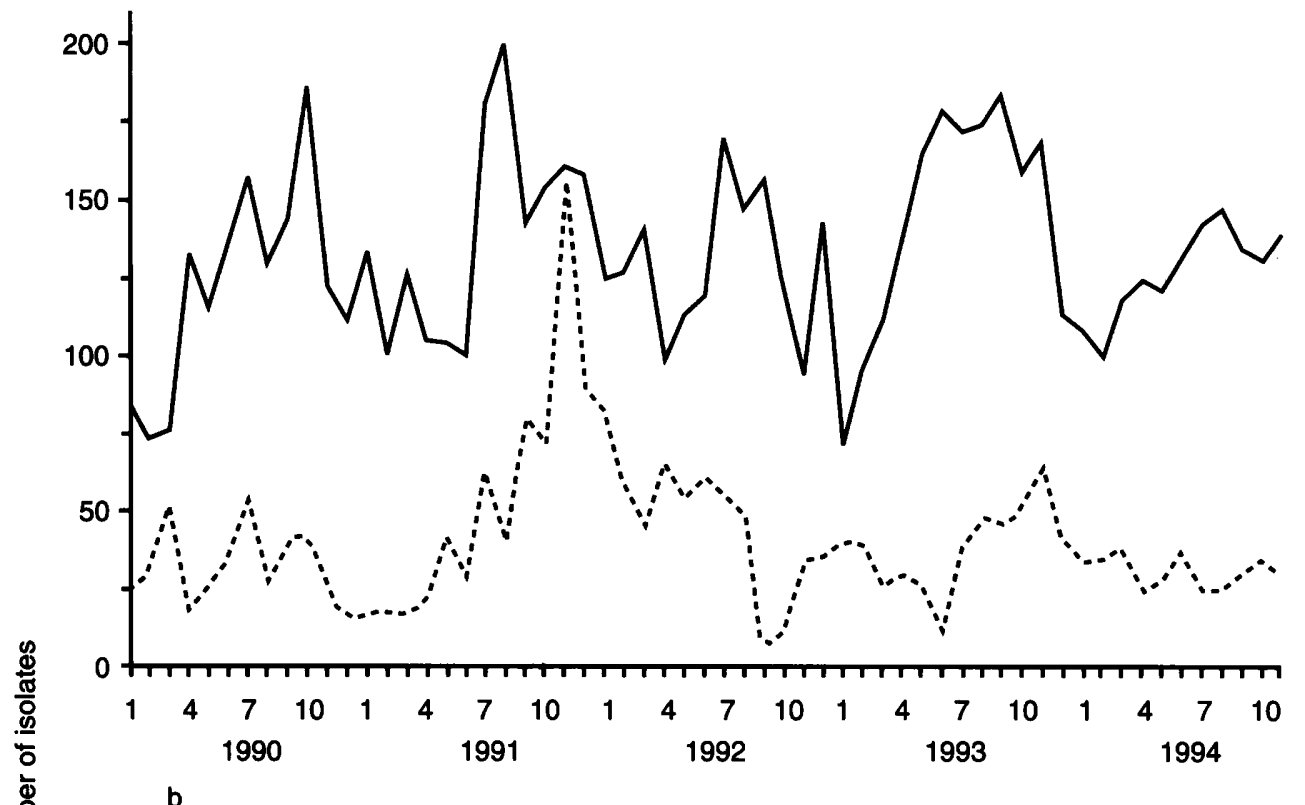

b

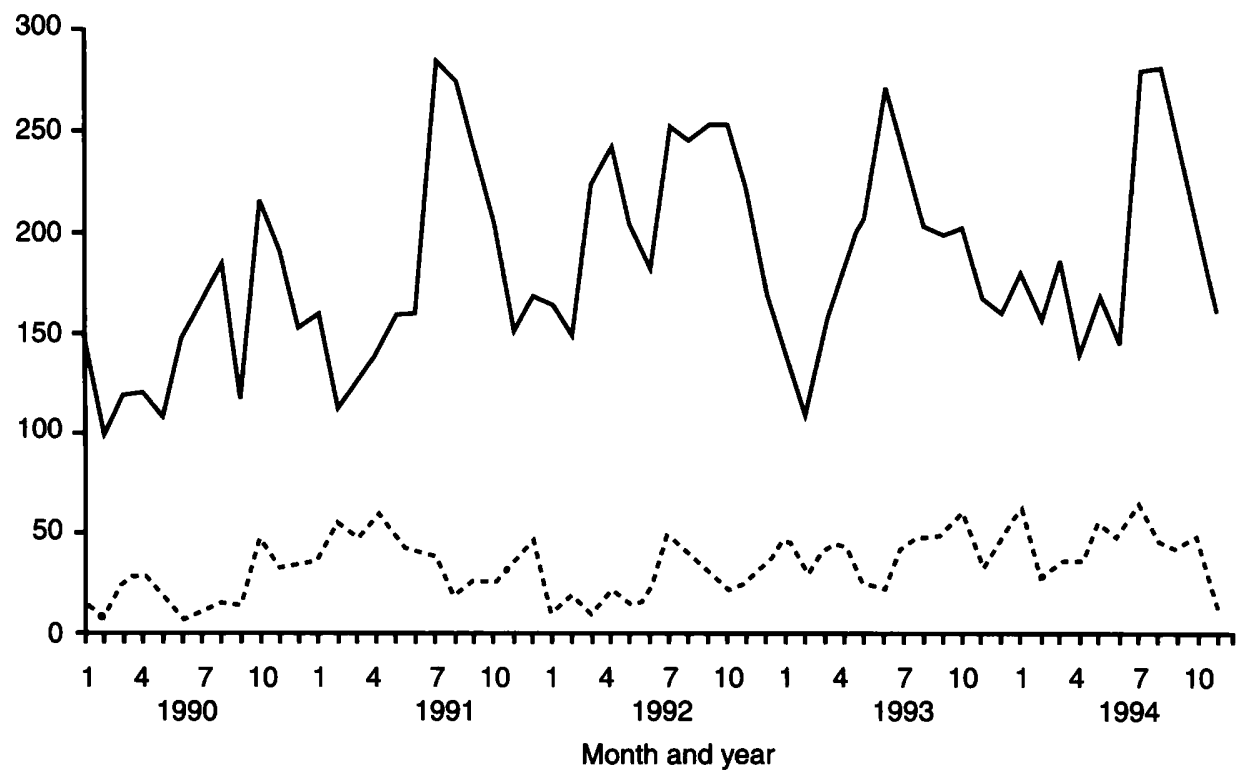

Fig. 1. Seasonal distribution of (a) Acinetobacter spp. and (b) $P$. aeruginosa isolated from patients in the general ward $(-)$ and the intensive care unit $(\cdots)$. 
1991, the isolation rate was constant with an average of 36 isolates/month. This increase in the number of Acinetobacter spp. in Nov. 1991 was caused by an increased number of positive surveillance cultures from the patients and the environment, obtained as part of an outbreak investigation. As suitable molecular typing methods were unavailable at that time, it was not possible to conduct a full-scale epidemiological investigation.

The observed seasonality prompted an examination of the monthly distribution of $P$. aeruginosa, coagulasenegative staphylococci and $E$. coli during the same period. A similar ward-dependent seasonal isolation rate of $P$. aeruginosa was seen. In the general ward, the largest number of isolates of $P$. aeruginosa was collected during June-Sept., 1990-1994 (Fig. 1), while in the ICU, the isolation rate remained steady with an average of 34 isolates/month. Unlike Acinetobacter spp. and $P$. aeruginosa, the incidence of coagulasenegative staphylococci and $E$. coli isolates was unaffected by seasonal changes (data not shown).

\section{Comparative distribution of Acinetobacter spp.} according to isolation site in patients in the general ward and ICU

In the general ward, $32.8,25.8,14.6$ and $11.4 \%$ of Acinetobacter isolates were from wound, urinary tract, lower respiratory tract and sputum specimens, respectively (Table 2). In the ICU, the isolates were mainly from lower respiratory tract specimens $(75.5 \%)$.

The distribution of $P$. aeruginosa amongst general ward patients was similar to that of Acinetobacter spp., with $22.4 \%$ of isolates from wound, $27.9 \%$ from urinary tract, $11.1 \%$ from lower respiratory tract and $28.3 \%$ from sputum specimens (Table 2). Likewise, the major isolation site in ICU patients was the lower respiratory tract $(61.6 \%)$.
The relative distributions of coagulase-negative staphylococci and $E$. coli differed from those of Acinetobacter spp. and $P$. aeruginosa (Table 2). Coagulase-negative staphylococci were found mainly in urinary tract, wound and blood specimens from patients in the general ward $(31.3,25.9$ and $20.4 \%$, respectively), and from $\mathrm{CSF}$ and i.v. catheters and lower respiratory tract specimens of ICU patients (31.0 and $29.9 \%$, respectively). In contrast, $E$. coli was isolated primarily from the urinary tract of patients in both wards (73.0 and $32.9 \%$, respectively).

\section{Comparative distribution of Acinetobacter spp. in bacteraemic patients in the general ward and ICU}

In total, there were 9104 bacteraemic episodes in hospitalised patients admitted between Jan. 1990 and Nov. 1994. Acinetobacter spp. accounted for 14.8 and $4.8 \%$ of all bacteraemic episodes in the ICU and general ward, respectively (Table 3 ). Acinetobacter spp. were the second most frequently encountered organisms, after coagulase-negative staphylococci, amongst all bacteria isolated from bacteraemic ICU patients.

The incidence of polymicrobial bacteraemic episodes amongst the four bacteria was highest with Acinetobacter spp. (25.2\%) (Table 3). The frequency of other organisms isolated simultaneously with $P$ aeruginosa, coagulase-negative staphylococci and $E$. coli was 15.5 , 13.7 and $14.6 \%$, respectively. When the types of organism isolated concurrently with each of the four groups were compared, similarity between Acinetobacter spp. and coagulase-negative staphylococci was observed (Table 4). More than half of the organisms isolated in conjunction with each of these two groups were skin colonisers and other non-fermenters likely to be acquired ectogenously by patients. This was in contrast to $P$. aeruginos $a$ and $E$. coli, where at least half of the co-existing organisms were probably of

Table 2. Distribution of Acinetobacter spp., P. aeruginosa, coagulase-negative staphylococci and $E$. coli according to isolation site in patients in the general ward and intensive care unit

\begin{tabular}{|c|c|c|c|c|c|c|c|c|}
\hline \multirow[b]{3}{*}{ Isolation site } & \multicolumn{8}{|c|}{ Percentage of isolates from } \\
\hline & \multicolumn{4}{|c|}{ General ward } & \multicolumn{4}{|c|}{ ICU } \\
\hline & $\begin{array}{c}\text { Acinetobacter } \\
\text { spp. } \\
(\mathrm{n}=5416)\end{array}$ & $\begin{array}{c}\text { PA } \\
(n=7253)\end{array}$ & $\begin{array}{c}\text { CNS } \\
(n=8059)\end{array}$ & $\begin{array}{c}E . \text { coli } \\
(\mathrm{n}=15401)\end{array}$ & $\begin{array}{c}\text { Acinetobacter } \\
\text { spp. } \\
(n=1630)\end{array}$ & $\begin{array}{c}\text { PA } \\
(n=941)\end{array}$ & $\begin{array}{c}\text { CNS } \\
(n=802)\end{array}$ & $\begin{array}{c}E . \text { coli } \\
(n=550)\end{array}$ \\
\hline Sputum & 11.4 & 28.3 & 3.1 & 1.0 & 5.2 & 13.3 & 3.2 & 2.3 \\
\hline LRT $^{*}$ & 14.6 & 11.1 & 3.3 & 0.8 & 75.5 & 61.6 & 29.9 & 20.9 \\
\hline Urinary tract* & 25.8 & 27.9 & 31.3 & 73.0 & 2.3 & 4.5 & 5.9 & 32.9 \\
\hline Wound* & 32.8 & 22.4 & 25.9 & 10.1 & 4.9 & 6.8 & 11.3 & 11.7 \\
\hline Blood & 6.9 & 3.3 & 20.4 & 8.8 & 3.8 & 0.8 & 9.2 & 2.0 \\
\hline Body fluid* & 5.8 & 5.4 & 5.7 & 6.0 & 5.3 & 11.1 & 9.4 & 28.9 \\
\hline Others* & 2.7 & 1.7 & 10.4 & 0.3 & 3.0 & 1.9 & 31.0 & 1.4 \\
\hline
\end{tabular}

PA, $P$. aeruginosa; CNS, coagulase-negative staphylococci; LRT, lower respiratory tract.

${ }^{*}$ LRT specimens included bronchoalveolar lavage, endotracheal and bronchial aspirates; urinary tract specimens included mid-stream, catheterised and nephrostomic urine; wound specimens included superficial and deep wound swabs; body fluid included bile, pleural, peritoneal, peritoneal dialysis and drain fluids; others included cultures from CSF and i.v. catheters. 
Table 3. The incidence of bacteraemia associated with Acinetobacter spp., $P$. aeruginosa, coagulase-negative staphylococci and $E$. coli in patients in the general ward and intensive care unit

\begin{tabular}{lcccc}
\hline & \multicolumn{3}{c}{ Percentage of bacteraemic episodes* } \\
\cline { 2 - 5 } Location & Acinetobacter spp. & PA & CNS & E. coli \\
\hline Bacteraemic episodes in general ward $(\mathrm{n}=8799)$ & 4.8 & 2.7 & 18.7 & 14.7 \\
Bacteraemic episodes in ICU $(\mathrm{n}=305)$ & 14.8 & 2.6 & 28.0 & 4.2 \\
Polymicrobial bacteraemic episodes (both locations) & 25.2 & 15.5 & 13.7 & 14.6 \\
\hline
\end{tabular}

$\mathrm{PA}, P$ a aruginosa; CNS, coagulase-negative staphylococci.

*Other organisms causing bacteraemia included Staphylococcus aureus, other members of the Enterobacteriaceae (e.g., Salmonella and Klebsiella spp.), non-fermenters (e.g., Xanthomonas and Pseudomonas spp.) and yeasts.

Table 4. Organisms isolated in conjunction with Acinetobacter spp., $P$. aeruginosa, coagulase-negative staphylococci and $E$. coli from episodes of polymicrobial bacteraemia

\begin{tabular}{|c|c|c|c|c|}
\hline \multirow[b]{2}{*}{ Organisms } & \multicolumn{4}{|c|}{ Percentage of polymicrobial episodes } \\
\hline & $\begin{array}{l}\text { Acinetobacter spp. } \\
\quad(\mathrm{n}=106)\end{array}$ & $\underset{(n=46)}{P A}$ & $\begin{array}{c}\text { CNS } \\
(n=222)\end{array}$ & $\begin{array}{c}\text { E. coli } \\
(\mathrm{n}=187)\end{array}$ \\
\hline CNS & 25.5 & 15.2 & $\ldots$ & 4.6 \\
\hline Other skin colonisers* & 9.4 & 4.3 & 30.2 & 5.5 \\
\hline Acinetobacter spp. & $\ldots$ & 6.5 & 9.6 & 2.5 \\
\hline Xanthomonas maltophilia & 9.4 & 2.1 & 8.9 & 0.0 \\
\hline Other non-fermenters* & 11.4 & 2.3 & 11.0 & 6.4 \\
\hline E. coli & 5.7 & 10.9 & 3.2 & $\ldots$ \\
\hline Klebsiella spp. & 7.5 & 10.9 & 2.8 & 30.0 \\
\hline Other enteric colonisers* & 8.5 & 13.0 & 2.1 & 5.5 \\
\hline Streptococcus and Enterococcus spp. & 16.9 & 17.4 & 12.4 & 27.4 \\
\hline Others* & 5.7 & 17.4 & 33.3 & 17.4 \\
\hline
\end{tabular}

PA, $P$. aeruginosa; $\mathrm{CNS}$, coagulase-negative staphylococci.

${ }^{*}$ Other skin colonisers included species of Bacillus and Corynebacterium; other non-fermenters included species of Pseudomonas and Flavobacterium; other enteric colonisers included other members of the Enterobacteriaceae; Others included $S$. aureus and species of Clostridium, Bacteroides, Aeromonas, Rhodotorula and Candida.

endogenous origin (e.g., members of the Enterobacteriaceae and streptococci). Furthermore, the genus Acinetobacter was unique in that it existed with organisms of ectogenous and endogenous sources in similar ratio.

\section{Antimicrobial susceptibility}

The susceptibility of Acinetobacter spp. to 11 antimicrobial agents has remained unchanged over the past 5 years. At least half of the glucose-oxidising isolates were insusceptible to most $\beta$-lactam agents (ampicillin, cephalothin, cefuroxime, ceftriaxone and amoxycillin + clavulanic acid), gentamicin and trimethoprim + sulphamethoxazole (Table 5). However, $55.4 \%$ of these isolates were sensitive to ceftazidime. Susceptibility to other aminoglycosides (netilmicin and amikacin) and the quinolone ofloxacin ranged between 66.4 and $72.7 \%$. Most of these isolates were susceptible to imipenem, with resistance detected in only $5.8 \%$ of the isolates. In contrast, the majority of non-glucoseoxidising isolates were susceptible to most antimicro- bial agents tested, except cephalothin which was active against only $14.1 \%$ of the isolates.

\section{Genotypic polymorphism}

Examples of amplification products obtained by PCR with (GTG) 5 as the arbitrary primer are shown in Fig. 2; 19 unique banding patterns were observed amongst the 60 clinical isolates identified presumptively as $A$. baumannii or the unnamed DNA group 13 . Each PCR profile contained one to six DNA fragments with sizes of $0.18-1.01 \mathrm{~kb}$. These profiles differed amongst isolates derived from patients residing in the same wards.

\section{Discussion}

Acinetobacter spp. have been isolated commonly from clinical specimens in this locality over the past 5 years, comprising $35 \%$ of non-fermenters, $11 \%$ of gramnegative bacilli and 7\% of all bacteria isolated (Table 1). These values are similar to the corresponding 
Table 5. The antimicrobial susceptibility of Acinetobacter spp. isolated during 1990-1994

\begin{tabular}{|c|c|c|}
\hline \multirow[b]{2}{*}{ Antimicrobial agent } & \multicolumn{2}{|c|}{ Percentage of isolates susceptible* } \\
\hline & $\begin{array}{l}\text { Glucose-oxidising strains } \\
\qquad(\mathrm{n}=7061)\end{array}$ & $\begin{array}{l}\text { Non-glucose-oxidising strains } \\
(n=410)\end{array}$ \\
\hline Ampicillin & 0.3 & 75.9 \\
\hline Cephalothin & 0.1 & 14.1 \\
\hline Cefuroxime & 3.5 & 77.9 \\
\hline Ceftriaxone & 4.7 & ND \\
\hline Ceftazidime & 55.4 & 65.0 \\
\hline Amoxycillin + clavulanic acid & 22.3 & 88.9 \\
\hline Imipenem & 94.2 & 100.0 \\
\hline Gentamicin & 47.9 & 95.3 \\
\hline Netilmicin & 66.4 & 96.9 \\
\hline Amikacin & 72.7 & 75.7 \\
\hline Trimethoprim + sulphamethoxazole & 49.1 & 86.1 \\
\hline Ofloxacin & 66.7 & 87.2 \\
\hline
\end{tabular}

ND, not determined.

* Susceptibility of isolates was determined by the disk diffusion method [18].

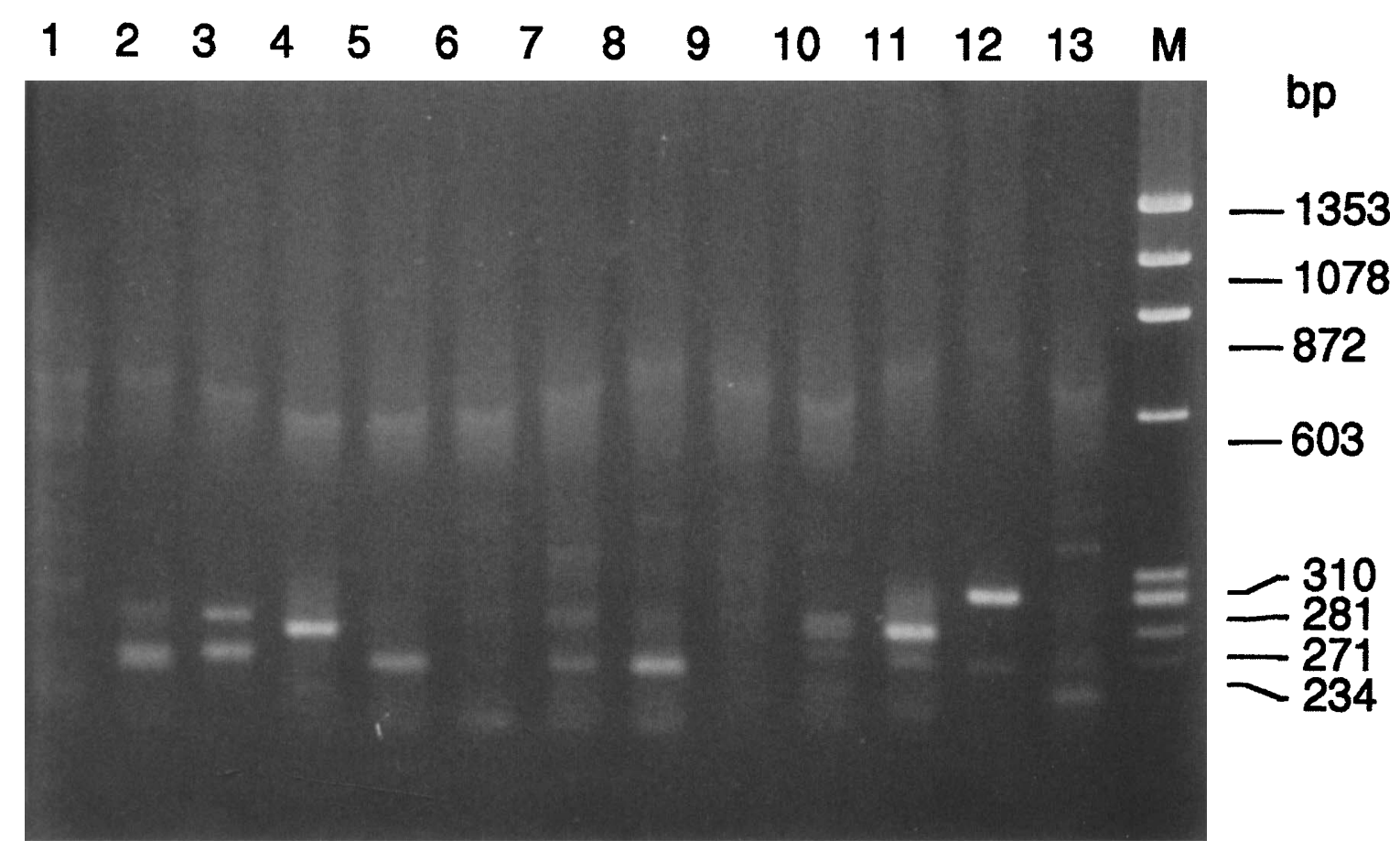

Fig. 2. Examples of amplified DNA fragments of glucose-oxidising Acinetobacter isolates (presumed to be $A$. baumannii or DNA group 13) generated by AP-PCR with (GTG) 5 as the primer. Lane M, DNA molecular size markers ( $\phi$ X174 DNA-Hae III); 1 and 9, negative control; 4, internal control (A. baumannii strain ATCC 19606); 2 and 8, isolates from different ICU patients; 3, 4, 7 and 10, isolates from different general ward patients; 5 and 6, isolates from patients admitted to the same general ward at different dates; 11-13, isolates from patients admitted to another general ward at different dates; all isolates were obtained from blood specimens.

figures of 37,12 and $7 \%$ reported in Taiwan and Singapore $[19,20]$.

The increase in the prevalence of nosocomial Acinetobacter spp. during summer has also been observed in the USA by the Centers for Disease Control [12]. In investigating invasive acinetobacter infections, it was found that $53 \%$ of 32 meningitis cases and $41 \%$ of 27 bacteraemic episodes occurred in summer $[13,21]$. The higher temperature and humidity of the ambient air in summer has been postulated to contribute to this peak incidence [22]. We suggest that if the warm weather is a contributing factor to the seasonality of acinetobacter infections, then a similar pattern for other organisms from environmental sources should be observed. Indeed, an annual increase of $P$. aeruginosa isolates during the summer months was evident (Fig. 1). The fact that the seasonal variation was observed in the general ward, but not in the ICU, further supported the proposition. In the early 
1990s, the ICU was the only air-conditioned ward. Hence it is not unexpected that the seasonal pattern was absent in the ICU as a constant room temperature was maintained. Moreover, central air-conditioning was extended to all general wards in early 1994, which coincided with and may account for the lack of any seasonal increase of Acinetobacter isolates in the same year. Therefore, the observation of seasonality in some reports, and its absence in others [14], could be explained by the variation in ambient temperature, or the lack of it in air-conditioned wards. However, we are unable to explain why the peak incidence of $P$. aeruginosa isolates persisted in 1994 after the installation of air-conditioning in all wards. It is possible that the organism's predilection for moist environments has contributed to its increased isolation during Hong Kong's humid summers.

The characteristics of acinetobacter infections were studied with a comparative approach. An attempt was made to correlate laboratory data with those of established nosocomial pathogens whose ecological reservoir was either related strongly to the hospital environment ( $P$. aeruginosa), skin (coagulase-negative staphylococci) or the gastrointestinal tract (E. coli). In comparing the relative distribution of Acinetobacter spp. with those of the reference organisms, it was hoped to draw a parallel to the type of infection with which it is associated. The relative distributions of Acinetobacter spp. and $P$. aeruginosa amongst the various isolation sites and the two patient populations were similar (Table 2). This suggests that the role played by Acinetobacter spp. in causing hospitalacquired infections in this region may be as prominent as that of $P$. aeruginosa.

The prevalence of acinetobacter infections differed amongst patients in different wards. In the general ward, almost $60 \%$ of Acinetobacter isolates were from wound and urinary tract specimens. In the ICU, isolates were cultured mainly from lower respiratory tract specimens. It seems likely that the bacterial reservoir differed between the two populations, probably with skin and urinary tract catheters in the former, and ventilators in the latter. This difference may reflect the overwhelming number of patients requiring mechanical ventilation in the ICU. Acinetobacter spp. are associated with endotracheal intubation and ventilation, and are the predominant pathogens causing ventilator-associated pneumonia $[23,24]$.

The prevalence of acinetobacter-positive blood cultures in this locality was higher than published data in which these organisms accounted for $<1 \%$ of total blood isolates [14,25]. Acinetobacter spp. were the second most common micro-organisms isolated from bacteraemic ICU patients (Table 3). They were isolated about three times more frequently from ICU patients than from patients in the general ward. In addition, these organisms were associated with the highest rate of polymicrobial bacteraemia (25.2\%). Polymicrobial bacteraemia associated with $P$. aeruginosa, coagulase-negative staphylococci and $E$. coli represented $13.7-15.5 \%$ of total bacteraemic episodes. These figures were in agreement with those reported elsewhere $[14,21,26-30]$. The high polymicrobial bacteraemic rate of Acinetobacter spp. may reflect the potential polymicrobial sources of infection. The organisms isolated in conjunction with Acinetobacter spp. could be ectogenous or endogenous in origin (Table 4). Therefore, direct or indirect contact with skin or foreign devices, as well as trauma that damages membrane integrity, are possible sources of bacteraemia. Seifert and Baginski [31] isolated glucose-oxidising $A$. baumannii from blood and vascular catheter-tip cultures in $45 \%$ of 31 bacteraemic ICU patients. Similarly, catheter-associated bacteraemia by the non-glucose-oxidising $A$. johnsonii was documented in 13 patients [32]. Peacock et al. [33] reported that $27 \%$ of $22 \mathrm{ICU}$ patients developed acinetobacter bacteraemia following the appearance of this organism in sputum.

It was of interest that, in terms of the body site- and ward-specific distribution, Acinetobacter spp. were similar to $P$. aeruginosa. However, in terms of the types of organism co-existing in blood specimens, Acinetobacter spp. were more comparable with coagulase-negative staphylococci. Yet unlike any of the reference organisms, Acinetobacter spp. existed with similar proportions of organisms that may have been acquired by the patient ectogenously or endogenously. Therefore the genus Acinetobacter was unique in that it had no dominant apparent portal of entry into the bloodstream.

As in previous reports, in-vitro resistance of glucoseoxidising strains of Acinetobacter spp. to multiple antibiotics was observed, with imipenem having the greatest likelihood of activity against these bacteria (Table 5). The antimicrobial susceptibility patterns of the glucose-oxidising and non-glucose-oxidising isolates were similar to those reported by Vila et al. [34] and Seifert et al. [35]. PCR with primers of a random sequence has been applied successfully to the molecular typing of A. baumannii [25,36,37]. When a simple tandem repeat, (GTG) $)_{5}$, was used as an arbitrary primer, 19 distinct profiles were obtained (Fig. 2), and no major epidemiological relationship was detected amongst the isolates, although some clusters of isolates were obtained simultaneously from patients in the same ward. Hence the presence of a dominant clone circulating in this hospital was not detected.

We thank P. Y. Chau and J. Y. C. Lo for critical reading of the manuscript; C. M. Chan, S. K. F. Lo and K. H. M. Yim for technical advice; K. S. Li and Y. L. Chan for retrieval of laboratory data; and the staff of the Department of Microbiology, Queen Mary Hospital, for their help in the collection of isolates. 


\section{References}

1. Hirai Y. Survival of bacteria under dry conditions; from a viewpoint of nosocomial infection. $J$ Hosp Infect 1991; 19: 191-200.

2. Bergogne-Berezin E, Joly-Guillou ML. An underestimated nosocomial pathogen, Acinetobacter calcoaceticus. J Antimicrob Chemother 1985; 16: 535-538.

3. Bouvet PJM, Grimont PAD. Taxonomy of the genus Acinetobacter with the recognition of Acinetobacter baumannii sp. nov., Acinetobacter haemolyticus sp. nov., Acinetobacter johnsonii sp. nov., and Acinetobacter junii sp., nov. and emended descriptions of Acinetobacter calcoaceticus and Acinetobacter lwoffi. Int J Syst Bacteriol 1986; 36: 228-240.

4. Bouvet PJM, Jeanjean S. Delineation of new proteolytic genomic species in the genus Acinetobacter. Res Microbiol 1989; 140: 291-299.

5. Tjernberg I, Ursing J. Clinical strains of Acinetobacter classified by DNA-DNA hybridization. APMIS 1989; 97: 595-605.

6. Dijkshoorn L, van Dalen R, van Ooyen A et al. Endemic acinetobacter in intensive care units: epidemiology and clinical impact. J Clin Pathol 1993; 46: 533-536.

7. Vila J, Marcos A, Llovet T, Coll P, Jimenez de Anta T. A comparative study of ribotyping and arbitrarily primed polymerase chain reaction for investigation of hospital outbreaks of Acinetobacter baumannii infection. J Med Microbiol 1994; 41: 244-249.

8. Go ES, Urban C, Burns $\mathrm{J}$ et al. Clinical and molecular epidemiology of acinetobacter infections sensitive only to polymyxin B and sulbactam. Lancet 1994; 344: 1329-1332.

9. Ratto P, Sordelli DO, Abeleira E, Torrero M, Catalano M. Molecular typing of Acinetobacter baumannii - Acinetobacter calcoaceticus complex isolates from endemic and epidemic nosocomial infections. Epidemiol Infect 1995; 114: 123-132.

10. Gerner-Smidt P. Acinetobacter: epidemiological and taxonomic aspects. APMIS 1994; 102 Suppl 47: 1-41.

11. Bergogne-Bérézin E, Joly-Guillou ML, Vieu JF. Epidemiology of nosocomial infections due to Acinetobacter calcoaceticus. $J$ Hosp Infect 1987; 10: 105-113.

12. Retailliau HF, Hightower AW, Dixon RE, Allen JR. Acinetobacter calcoaceticus: a nosocomial pathogen with an unusual seasonal pattern. $J$ Infect Dis 1979; 139: 371-375.

13. Siegman-Igra Y, Bar-Yosef S, Gorea A, Avram J. Nosocomial Acinetobacter meningitis secondary to invasive procedures: report of 25 cases and review. Clin Infect Dis 1993; 17: 843849.

14. Tilley PAG, Roberts FJ. Bacteremia with Acinetobacter species: risk factors and prognosis in different clinical settings. Clin Infect Dis 1994; 18: 896-900.

15. Lortholary O, Fagon J-Y, Hoi AB et al. Nosocomial acquisition of multiresistant Acinetobacter baumannii: risk factors and prognosis. Clin Infect Dis 1995; 20: 790-796.

16. Ho PL, Yuen KY, Yam WC, Wong SSY, Luk WK. Changing patterns and susceptibilities of blood, urinary and respiratory pathogens in Hong Kong. $J$ Hosp Infect (in press).

17. Barrow GI, Feltham RKA (eds). Cowan and Steel's manual for the identification of medical bacteria, 3rd edn. Cambridge, Cambridge University Press. 1993: 54, 113, 135.

18. National Committee for Clinical Laboratory Standards. M2-A4. Performance standards for antimicrobial disk susceptibility tests, 4th edn. Approved Standard. Villanora, Pennsylvania, NCCLS. 1990
19. Zhang Y. [A two-year prospective survey on nosocomial infections]. Chung Hua I Hsueh Tsa Chih Taipei 1991; 71: 253-256.

20. Department of Pathology, Singapore General Hospital Annual Report. 1991: 66.

21. Smego RA. Endemic nosocomial Acinetobacter calcoaceticus bacteremia. Clinical significance, treatment and prognosis. Arch Intern Med 1985; 145: 2174-2179.

22. Reynolds RC, Cluff LE. Infection of man with Mimeae. Ann Intern Med 1963; 58: 759-767.

23. Buxton AE, Anderson RL, Weerdegar D, Atlas E. Nosocomial respiratory tract infection and colonization with Acinetobacter calcoaceticus. Epidemiologic characteristics. Am J Med 1978; 65: 507-513.

24. Jimenez $\mathrm{P}$, Torres $\mathrm{A}$, Rodriguez-Roisin $\mathrm{R}$ et al. Incidence and etiology of pneumonia acquired during mechanical ventilation. Crit Care Med 1989; 17: 882-885.

25. Struelens MJ, Carlier E, Maes N, Serruys E, Quint WGV, van Belkum A. Nosocomial colonization and infection with multiresistant Acinetobacter baumannii: outbreak delineation using DNA macrorestriction analysis and PCR-fingerprinting. $J$ Hosp Infect 1993; 25: 15-32.

26. Centers for Disease Control. Nosocomial infection surveillance 1984. MMWR CDC Surveill Summ 1986; 35: 17SS-29SS.

27. Gallagher PG, Watanakunakorn C. Pseudomonas bacteremia in a community teaching hospital, 1980-1984. Rev Infect Dis 1989; 11: 846-852.

28. Cooper GS, Havlir D, Shlaes DM, Salata RA. Polymicrobial bacteremia in the late 1980s: predictors of outcome and review of the literature. Medicine 1990; 69: 114-123.

29. Mallolas J, Gatell JM, Miró JM, Marco F, Soriano E. Epidemiologic characteristics and factors influencing the outcome of Pseudomonas aeruginosa bacteremia. Rev Infect Dis 1990; 12: 718-719.

30. Gransden WR, Eykyn SJ, Phillips I, Rowe B. Bacteremia due to Escherichia coli: a study of 861 episodes. Rev Infect Dis 1990; 12: 1008-1018.

31. Seifert H, Baginski R. The clinical significance of Acinetobacter baumannii in blood cultures. Int J Med Microbiol Virol Parasitol Infect Dis 1992; 277: 210-218.

32. Seifert H, Strate A, Schulze A, Pulverer G. Vascular catheterrelated bloodstream infection due to Acinetobacter johnsonii (formerly Acinetobacter calcoaceticus var. lwoffi): report of 13 cases. Clin Infect Dis 1993; 17: 632-636.

33. Peacock JE, Sorrell L, Sottile FD, Price LE, Rutala WA. Nosocomial respiratory tract colonization and infection with aminoglycoside-resistant Acinetobacter calcoaceticus var. anitratus: epidemiological characteristics and clinical significance. Infect Control Hosp Epidemiol 1988; 9: 302-308.

34. Vila $\mathrm{J}$, Marcos A, Marco $\mathrm{F}$ et al. In vitro antimicrobial production of $\beta$-lactamases, aminoglycoside-modifying enzymes, and chloramphenicol acetyltransferase by and susceptibility of clinical isolates of Acinetobacter baumannii. Antimicrob Agents Chemother 1993; 37: 138-141.

35. Seifert H, Baginski R, Schulze A, Pulverer G. Antimicrobial susceptibility of Acinetobacter species. Antimicrob Agents Chemother 1993; 37: 750-753.

36. Gräser Y, Klare I, Halle E et al. Epidemiological study of an Acinetobacter baumannii outbreak by using polymerase chain reaction fingerprinting. J Clin Microbiol 1993; 31: 2417-2420.

37. Marcos MA, Jimenez de Anta MT, Vila J. Correlation of six methods for typing nosocomial isolates of Acinetobacter baumannii. J Med Microbiol 1995; 42: 328-335. 